\title{
ITER work is shared out
}

\section{Washington}

AT the third attempt, the four international partners planning to build the world's most advanced tokamak fusion reactor have agreed on a site from which to coordinate the machine's design. Assuming that each of the United States, the European Communities (EC), Japan and the Soviet Union decide to continue funding the project, work on the $\$ 1,000$ million six-year engineering design phase for the International Thermo-nuclear Experimental Reactor (ITER) should begin before the end of the year, led by a director based in San Diego, California.

But to forge agreement at a meeting last week in Reston, Virginia, negotiators had to abandon the idea of concentrating the international design team at a single site. Attempts to agree on a single site at meetings in Japan and Germany earlier this year ended in deadlock, with the United States, EC and Japan each arguing that they should be the country to host the design work.

The design team will now be split among three sites: Garching in Germany, Naka in Japan, and the lead site in San Diego. The Soviet Union and Japan will co-chair a council to oversee the project, which will meet in Moscow. The key job of directing the three design teams has been earmarked for a fusion scientist from the EC, making Paul Henri Rebut, who now heads the EC's Joint European Torus fusion project, the current leading contender.

Stephen Dean, president of the industry group Fusion Power Associates, believes that the division of work among sites will not be a major problem. A large proportion of the design work was always intended to be delegated to scientists working in their home countries, he points out.

Dean says that an equitable agreement, allowing each of the partners to claim a share of the prestige associated with hosting the project, was important "to maintain political enthusiasm" for ITER in each of the participating countries. Given that commercial fusion power is thought to lie at least 50 years away, and that the ITER project alone is expected to cost $\$ 4,900$ million by the time it is completed early next century, careful nurturing of political support for the project is crucial to quiet nay-sayers during decades of basic research.

The goal of the engineering design phase is to produce a detailed blueprint for the reactor's construction. But, according to Dean, the first year or more may be spent redefining much of the basic 'conceptual design', completed in December 1990 after three years' work by an international team of researchers based in
Garching.

Earlier this year, an independent review of ITER's conceptual design, carried out for the US Department of Energy, recommended that the torus used to contain the reactor's plasma should be built with a higher 'aspect ratio' than was suggested by the Garching team. Essentially, this means building "a skinnier doughnut" to contain the plasma, says Dave Baldwin, from the Lawrence Livermore National Laboratory, who led the Department of Energy review.

Recent experimental findings at the Princeton Plasma Fusion Laboratory and on the recently upgraded Japanese JT-60 reactor, which came too late to influence the ITER design work in Garching, have shown that increasing a tokamak's aspect ratio can improve the retention of heat in the plasma, Baldwin says.

Because fusion researchers are still struggling to achieve 'break even' in tokamak reactors - the point at which the amount of energy produced by fusion reactions equals the energy input needed to heat the plasma - this is considered an important result.

Peter Aldhous

\section{Science societies target station}

Washington

LOBBYING to kill funding for the space station Freedom reached a peak last week, with each member of the Senate receiving a letter signed by the presidents of 14 leading scientific societies, urging them not to fund the station at the expense of other scientific projects. The letter warns that, in addition to squeezing the National Aeronautics and Space Administration's space science budget, the escalating costs of Freedom could seriously affect the National Science Foundation's spending in future years.

The signatories to the letter include the American Chemical Society, the American Geophysical Union, the American Physical Society, the American Society of Zoologists and Sigma Xi. But even this concerted effort had little effect. The Senate Appropriations Committee voted to provide $\$ \mathbf{2 , 0 2 0}$ million for the station in $\mathbf{1 9 9 2 ,}$ the full amount requested by President George Bush, and \$120 million more than agreed on the floor of the House of Representatives last month (see Nature 351,$507 ; 13$ June 1991). The full Senate is this week expected also to endorse spending on Freedom.

\section{Sun, sea and shadow}

\author{
IMAGE \\ UNAVAILABLE \\ FOR COPYRIGHT \\ REASONS
}

A satellite view of the Moon's shadow, travelling across the Pacific Ocean towards Baja California, Mexico, during the total solar eclipse of 11 July. Measurement of this shadow provides a rare opportunity to calculate the precise diameter of the Sun - data used to examine the influence of variation in solar diameter on cli- mate. Unfortunately, direct observations of the solar corona during the eclipse, made from telescopes at Mauna Kea, in Hawaii, were hampered somewhat by the scattering of sunlight caused by volcanic aerosols released into the atmosphere by the recent eruptions of Mounts Unzen and Pinatubo. 